\title{
Particle size tuning in silver-polyacrylonitrile nanocomposites
}

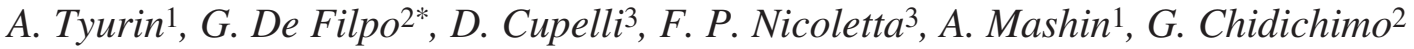 \\ ${ }^{1}$ Department of Applied Physics \& Microelectronics, Lobachevsky State University, 603022 Nizhni Novgorod, Russia \\ ${ }^{2}$ Department of Chemistry, University of Calabria, 87036 Rende (CS), Italy \\ ${ }^{3}$ Department of Pharmaceutical Sciences, University of Calabria, 87036 Rende (CS), Italy
}

Received 2 September 2009; accepted in revised form 7 November 2009

\begin{abstract}
Silver-polyacrylonitrile (Ag-PAN) nanocomposites were in situ synthesized by simultaneous polymerization of acrylonitrile and reduction of silver ions, starting from mixtures of silver nitrate $\left(\mathrm{AgNO}_{3}\right)$, acrylonitrile (AN), and UV photoinitiator (IN). The films obtained proved to be transparent and were characterized by a homogeneous dispersion of Ag nanoparticles within the PAN matrix without any macroscopic agglomeration. The particle size and number density were found to depend on both precursor salt and UV photoinitiator weight percentages. Optical and electrical properties were investigated as a function of both $\mathrm{AgNO}_{3}$ and IN amounts, too. We found that it is possible to finely tailor the metal nanoparticle size and number density and, consequently, the film optical and electrical response by adjusting the amounts of precursor salt and UV photoinitiator in the initial mixtures.
\end{abstract}

Keywords: nanocomposites, nanomaterials, electrical properties, optical properties

\section{Introduction}

Noble metal nanoparticles dispersed in insulating matrices have attracted the interest of many researchers from both applied and theoretical points of view [1-8]. In facts, such nanocomposites exhibit specific optical and electrical properties, making them suitable as advanced technological materials to be used as novel sensors, in catalytic applications, for energy storage, etc. [9-11].

Polymers represent suitable matrices for the preparation of metal nanocomposites being generally low cost materials characterized by an easy processing. For practical applications it is important to get nanoparticles uniformly dispersed in polymer matrices, but, due to their high surface reactivity, metal nanoparticles tend to aggregate into larger dimension clusters. Composites made by mechanical mixing of metal nanoparticles and molten polymers generally lead to inhomogeneous particle dis- persions. As a consequence, various approaches have been proposed to manufacture metal nanocomposites including ball milling, coevaporation and sputtering of metals and polymers, plasma polymerization, and new synthetic procedures [12-15]. Among these last approaches, it is important to mention the use of different agents in order to increase nanoparticle stability, the simultaneous photoinduced electron transfer and cationic polymerization, the thermal and UV in situ polymerizations [16-22]. Recently, UV in situ polymerization has gained a lot of attention. In fact, UV photochemically assisted polymerizations are characterized by low temperature conditions and faster polymerization rates, resulting in the formation, during the polymer network growth, of homogeneously dispersed metal nanoparticles without the use of further solvents and reducing agents. The UV photochemically generated radicals, being electron

*Corresponding author, e-mail: defilpo@unical.it

(c) BME-PT 
donor species, are able to simultaneously polymerize monomers and reduce the metal salts, which will form metal nanoparticles.

Acrylonitrile is an important polymer used principally in the manufacture of synthetic fibers. Silver is a well known metal characterized by a high electrical conductivity, good optical properties, and interesting oxidative catalysis performance.

In this paper we have investigated the in situ synthesis of silver-poliacrylonitrile (Ag-PAN) nanocomposites by a UV photoinduced process. 2,2'dimethoxy-2-phenil acetophenone was used as UV photoinitiator (IN) to generate electron donating radicals. Subsequent oxidation of these radicals to corresponding cations in the presence of silver nitrate $\left(\mathrm{AgNO}_{3}\right)$ and acrylonitrile ( $\left.\mathrm{AN}\right)$ leads to the simultaneous formation of silver ( $\mathrm{Ag}$ ) nanoparticles and polymerization of polyacrylonitrile (PAN). Nanocomposite morphology, electrical and optical properties were found to depend both on $\mathrm{AgNO}_{3}$ and IN amounts in the starting mixtures, allowing a fine tailoring of both size and number density of metal particles and, consequently, the properties of Polymer Dispersed Metal NanoParticles (PDMNPs).

\section{Experimental part}

Acrylonitrile monomer and silver nitrate were both supplied by Aldrich, Milan, Italy. 2,2'dimethoxy-2phenyl acetophenone (Aldrich, Milan, Italy) was used as UV photoinitiator. $\mathrm{AN} / \mathrm{AgNO}_{3} / \mathrm{IN}$ mixtures were prepared in vials by mixing the appropriate wt. amounts of components. $\mathrm{AgNO}_{3}$ was varied in the range from 2 to $25 \mathrm{wt} \%$, while IN was varied from 0 to $25 \mathrm{wt} \%$. Then, a small quantity of mixtures was introduced by capillary action into home made cells, whose thickness was set to be $25 \mu \mathrm{m}$ by glass spheres. Glass substrates had a $120 \mathrm{~nm}$ indium tin oxide conductive layer for the successive electric characterization. After filling, cells were exposed at room temperature $\left(20^{\circ} \mathrm{C}\right)$ for $10 \mathrm{~min}$ to the UV light from a high pressure lamp (HPK 125, Philips, Eindhoven, Nederlands, average power $110 \mu \mathrm{W} / \mathrm{cm}^{2}$ ) in order to generate free radicals in the samples and to cause the simultaneous polymerization of $\mathrm{AN}$ in PAN and reduction of $\mathrm{Ag}^{+}$ions in metal silver. Film samples were characterized by X-ray using a 1730/10 diffractometer (Philips, Eindhoven, Nederlands) using $\mathrm{CuK}_{\alpha}$ radi- ation and $0.5^{\circ} 2 \theta \mathrm{min}^{-1}$. FT-IR measurements were carried out by a Fourier Transform Infrared spectrometer (FT-IR Jasco 4200, Jasco Europe, Cremella, Italy) in the spectral range 4000 $400 \mathrm{~cm}^{-1}$. The morphology of ultra-thin sections $(80 \mathrm{~nm})$ of silver particles in PAN was investigated by a transmission electron microscope (TEM, Zeiss EM 900, Carl Zeiss S.p.A., Milan, Italy). Conductivity measurements were carried in the frequency range from $20 \mathrm{~Hz}$ to $1 \mathrm{MHz}$ with a LCR meter (Agilent 4284A, Agilent Technologies Italia S.p.A., Cernusco sul Naviglio, Italy). The applied voltage over the entire frequency range was $1 \mathrm{~V}$, which is the typical voltage used in other similar measurements [23]. The composite conductivity was calculated from geometrical factors. The film absorption spectra were determined by a UV-Vis spectrometer (Jasco 550V, Jasco Europe, Cremella, Italy) in the wavelength range of 300-800 $\mathrm{nm}$.

\section{Results and discussion}

It is known that the electrical and optical properties of metal nanoparticles-polymer composites strongly depend on particle morphology. In order to understand the main idea followed in this work, we recall the three reactions that can occur during the irradiation of silver nitrate, acrylonitrile and photoinitiator mixtures. Hong et al. have shown that silver ions and AN form the following complex when mixed [24]:

$$
\mathrm{Ag}^{+}+2 \mathrm{AN} \leftrightarrows\left[\mathrm{Ag}(\mathrm{AN})_{2}\right]^{+}
$$

If the solution is irradiated by ultraviolet light, the photoinitiator will induce the free radical polymerization of AN monomers, and, simultaneously, $\mathrm{Ag}^{+}$ is reduced to metallic silver according to the reaction scheme 1 reported in Figure 1.

The presence of photoinitiator allows the further reactions reported in the reaction schemes 2 and 3 of Figure 1.

Reaction scheme 1 describes the simultaneous reduction of silver ions and the cationic polymerization of AN, while reaction scheme 2 shows the UV free radical polymerization of AN. Reaction scheme 3 is equivalent to reaction scheme 1 (in this case the cationic polymerization of $\mathrm{AN}$ is mediated by IN), and both are responsible for nanoparticle nucleation (and growth) and AN polymerization. Reaction scheme 2, acting only on polymer growth, 


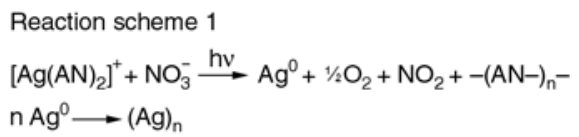

Reaction scheme 2

$\mathrm{IN}+\mathrm{hv} \longrightarrow \mathrm{IN}^{*}$

$\mathrm{AN}+\mathrm{IN}^{*} \longrightarrow \mathrm{AN}^{*}-\mathrm{IN}$

$(\mathrm{AN})_{n}+\mathrm{AN}^{*}-\mathrm{IN} \longrightarrow(\mathrm{AN})_{n}-\mathrm{AN}^{*}-\mathrm{IN}$

Reaction scheme 3

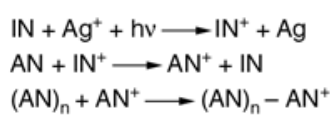

Figure 1. Reaction schemes for mixtures of $\mathrm{AN}, \mathrm{AgNO}_{3}$ and IN (polymer growth and nanoparticle nucleation) (nanoparticle growth)

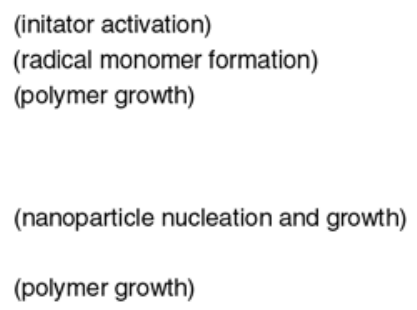

could allow one to control film morphology by a simple change in photoinitiator loading. As a consequence, we have investigated the morphology, the electrical and optical properties of PDMNP composites as a function of both silver nitrate and photoinitiator wt. percentages.

\subsection{Morphology analysis of PDMNPs}

Figure 2 shows the typical X-ray diffraction spectra of an $\mathrm{Ag} / \mathrm{PAN}$ nanocomposite film $\left(\left[\mathrm{AgNO}_{3}\right]=\right.$ $15 \mathrm{wt} \%$ and $[\mathrm{IN}]=10 \mathrm{wt} \%)$. The broad peak centered at $2 \theta=21^{\circ}$ can be associated with the amorphous phase of pure PAN, while the sharp peak at $16^{\circ}$ corresponds to the orthorhombic PAN reflection (100). The other peaks $\left(2 \theta=38^{\circ}, 2 \theta=44^{\circ}\right.$, and $2 \theta=65^{\circ}$ ) correspond to the (111), (200) and (220) crystalline planes of face centered cubic silver, which are consistent with standard values and confirm the $\mathrm{Ag}$ reduction and growth.

Figure 3 shows the FT-IR spectra of pure AN and $\mathrm{Ag} / \mathrm{PAN}$ nanocomposite film $\left(\left[\mathrm{AgNO}_{3}\right]=15 \mathrm{wt} \%\right.$

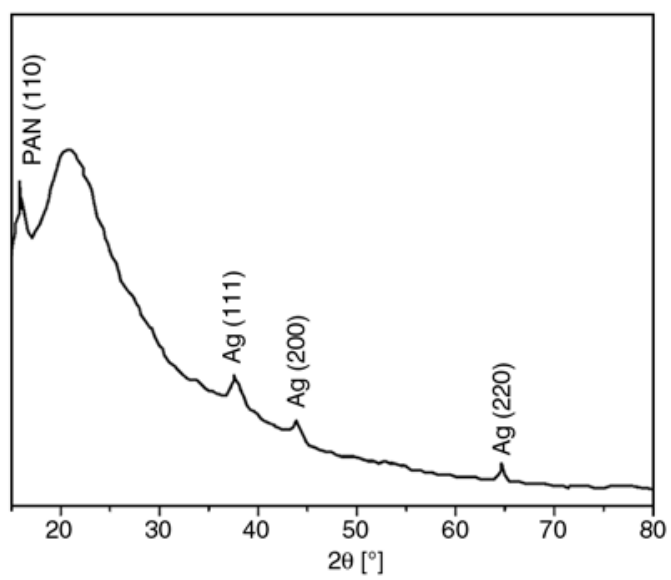

Figure 2. X-ray diffraction spectra of Ag/PAN nanocomposite $\left([\mathrm{IN}]=10 \mathrm{wt} \%\right.$ and $\left.\left[\mathrm{AgNO}_{3}\right]=15 \mathrm{wt} \%\right)$

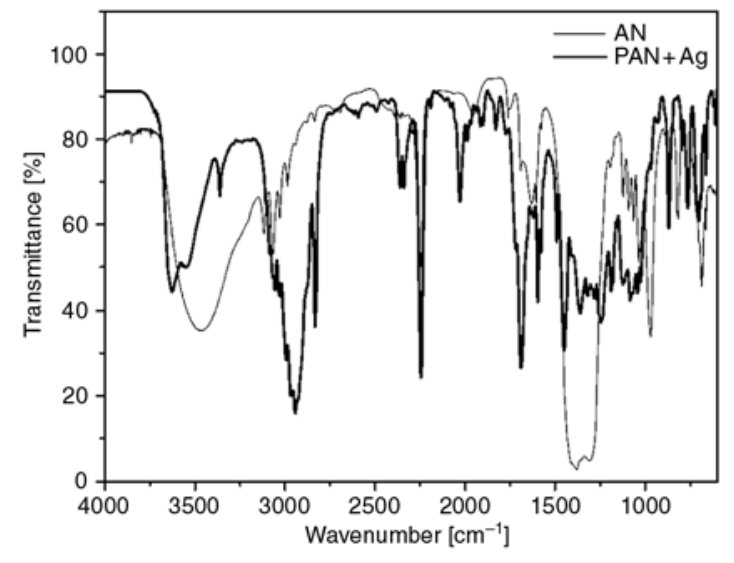

Figure 3. FT-IR spectra of pure AN and Ag/PAN nanocomposite $\left([\mathrm{IN}]=10 \mathrm{wt} \%\right.$ and $\left[\mathrm{AgNO}_{3}\right]=$ $15 \mathrm{wt} \%)$

and $[\mathrm{IN}]=10 \mathrm{wt} \%)$. By comparing the absorption bands it is evident the polymerization of AN from the disappeareance of the absorption band at $967 \mathrm{~cm}^{-1}$ ( $\mathrm{C}=\mathrm{C}$ bond $)$ and the appeareance of an absorption band in the range $3000-2900 \mathrm{~cm}^{-1}$ (aliphatic $\mathrm{CH}$ ).

TEM pictures allow a quantitative morphology analysis of $\mathrm{Ag} / \mathrm{PAN}$ nanocomposite films. Let's recall first the behaviour of nanoparticle size, $d$, and number density, $N D$, when the silver nitrate amount is increased at constant photoinitiator loading. As we found (data not shown) in agreement with the pictures reported in references 18 and 22, when the synthesis of Ag/PAN nanocomposites is achieved by a simultaneous polymerization and reduction approach, silver nanoparticles are well dispersed, their size distribution is uniform with spherical shape, and no agglomeration is evident. In addition, the diameter of Ag grains increases, while their number density decreases as silver nitrate wt. concentration increases in the sample compositions at constant photoinitiator amount. On the contrary, if 
the $\left[\mathrm{AgNO}_{3}\right]$ is kept constant and [IN] is increased, we observed large average particle sizes at lower IN wt. concentration and smaller average particle sizes for increasing IN wt. concentration. Figure 4 shows the typical TEM pictures of Ag/PAN nanocomposites as a function of initiator wt. percentage at constant metal precursor percentage $\left(\left[\mathrm{AgNO}_{3}\right]=15 \mathrm{wt} \%\right)$. In particular, at lower lower IN wt. concentration ([IN] $=2 \mathrm{wt} \%)$ the silver particle size is around $11 \mathrm{~nm}$ and decreases to the value of $1-2 \mathrm{~nm}$ for larger IN amounts ([IN] $=20$ and $25 \mathrm{wt} \%$ ). The increase of $\mathrm{AgNO}_{3}$ loading to values larger than $25 \mathrm{wt} \%$ causes the appereance of some silver aggregates dispersed in the PAN matrices.
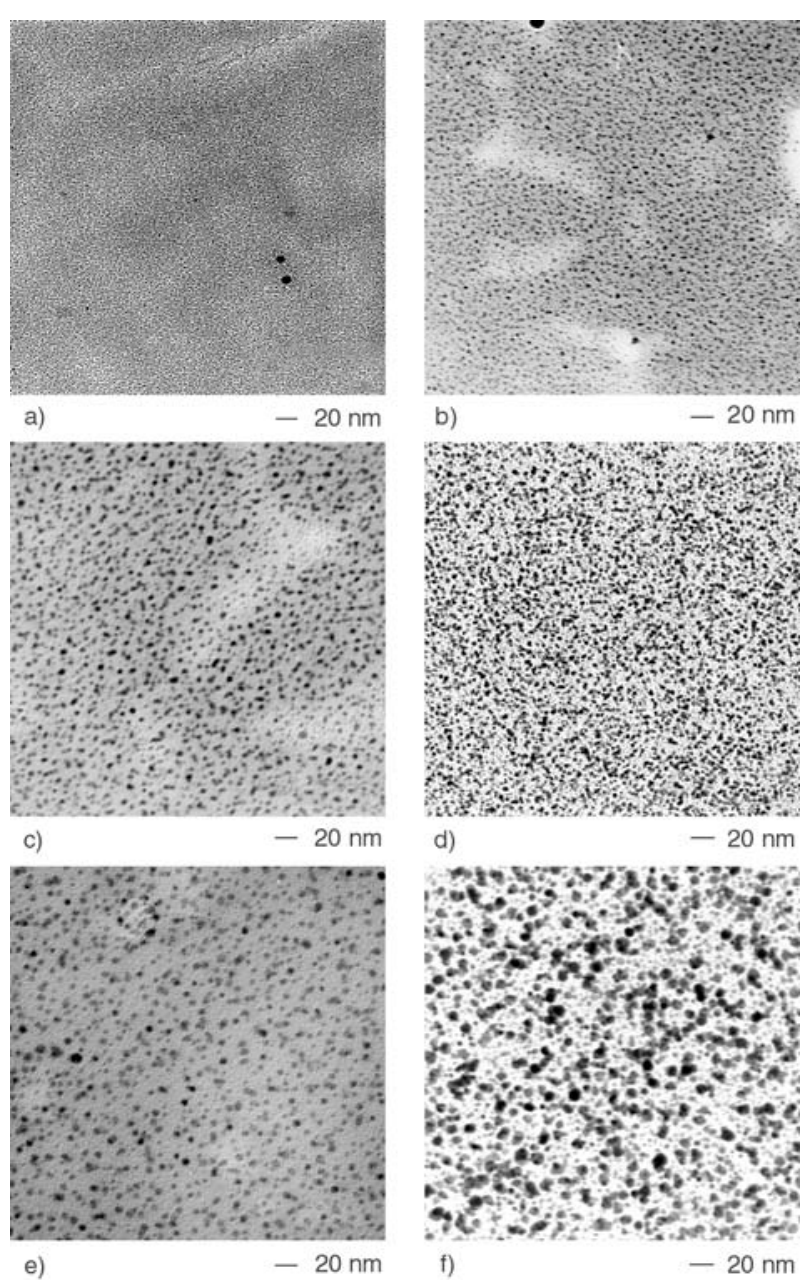

Figure 4. TEM pictures of $\mathrm{Ag} / \mathrm{PAN}$ nanocomposite films at a constant silver nitrate wt. percentage, $([\mathrm{AgNO} 3]=15 \mathrm{wt} \%)$ : a) $[\mathrm{IN}]=25 \mathrm{wt} \%$,

b) $[\mathrm{IN}]=20 \mathrm{wt} \%, \mathrm{c})[\mathrm{IN}]=15 \mathrm{wt} \%$,

d) $[\mathrm{IN}]=10 \mathrm{wt} \%, \mathrm{e})[\mathrm{IN}]=5 \mathrm{wt} \%$,

f) $[\mathrm{IN}]=2 \mathrm{wt} \%$. Silver nanoparticles are well dispersed and no agglomeration is evident. Metal nanoparticles possess almost uniform size distribution with spherical shape.
Results are more evident in Figures 5 and 6, where the average size and number density of $\mathrm{Ag}$ particles as a function of IN wt. percentage at constant metal precursor percentage $\left(\left[\mathrm{AgNO}_{3}\right]=15 \mathrm{wt} \%\right)$ are plotted.

The observed Ag particle sizes are characterized by a very narrow size distribution as PAN plays the role of protective agent against nanoparticle diffusion and agglomeration. As IN concentration increases the particle diameter decreases, but, at the same time, their number density increases. Such results are in agreement with expectations as the increase of inititiator concentration results in a faster polymerization of AN and, consequently, in a faster increase of sample viscosity and decrease of silver diffusion leading to a larger number of small size metal particles. In addition, it is expected that the reaction scheme 2 in Figure 1 should depress the first line of reaction scheme 1 if one increases

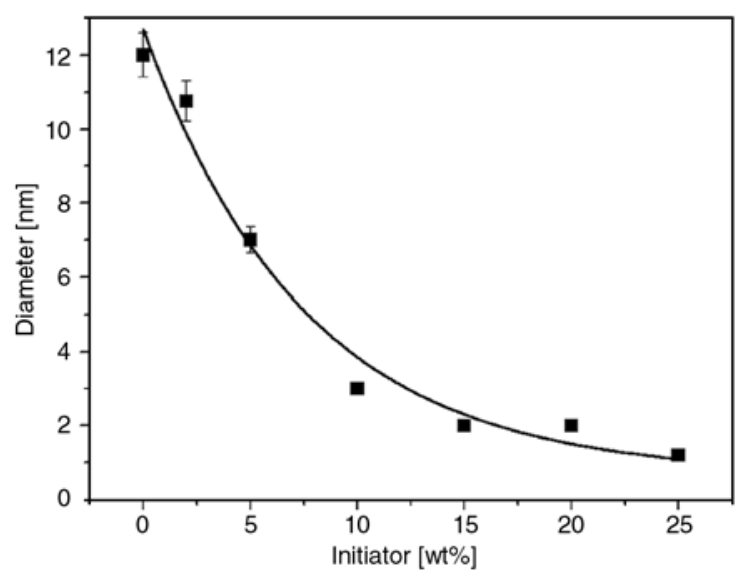

Figure 5. Average size of Ag particles as a function of initiator wt. percentage at constant metal precursor percentage $\left(\left[\mathrm{AgNO}_{3}\right]=15 \mathrm{wt} \%\right)$

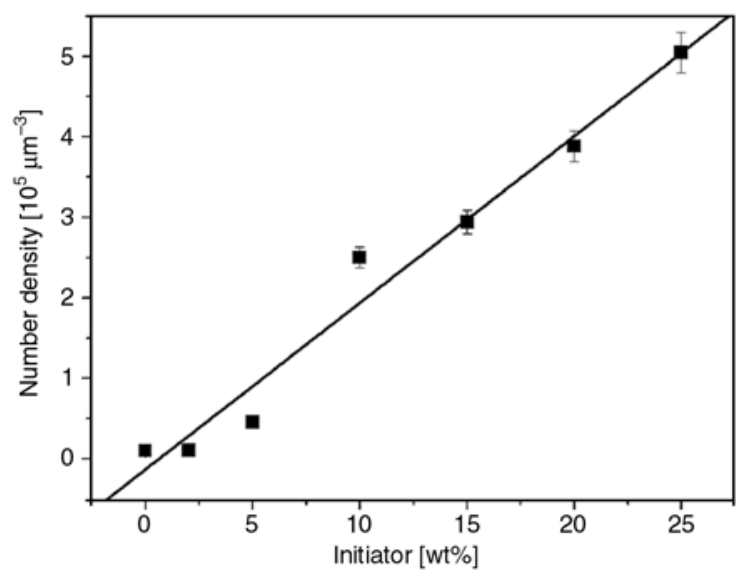

Figure 6. Average number density of Ag particles as a function of initiator wt. percentage at constant metal precursor percentage $\left(\left[\mathrm{AgNO}_{3}\right]=15 \mathrm{wt} \%\right)$ 
[IN], as the photon number is reduced by the reaction reported in line 3 of scheme 2 .

The calculation of metal silver volume fraction (or filling factor, $F F$ ) in our samples was performed by using the simple Equation (1):

$$
F F=\frac{V_{\mathrm{Ag}}}{V_{\text {tot }}}=\frac{4}{3} \pi R^{3} N D
$$

where $V_{\mathrm{Ag}}$ and $V_{t o t}$ are the volumes of Ag nanoparticles and observed sample, respectively. The behaviour of $F F$ vs. [IN] is reported in Figure 7 and is in agreement with expectations. So, both metal precursor and photoinitiator concentrations can control particle size and number density. For the sake of completeness, we must stress that temperature can affect particle morphology, acting on the reaction rate constants and translational diffusion coefficients. Work is in progress in order to investigate the influence of temperature on morphology.

The presence of an UV photoinitiator in our mixtures is important. In fact, in the absence of photoinitiator and low wt. percentage of silver nitrate (less than $15 \mathrm{wt} \%$ ) the polymerization of acrylonitrile does not occur within reasonable irradiation times ( 1 hour). In addition, films turn coloured for larger percentages of $\mathrm{AgNO}_{3}$ as shown in Figure 8. Unwanted crystallization of un-reacted silver nitrate can occur as the salt solubility in PAN is lower than that in $\mathrm{AN}$, leading to a dramatic increase of light scattering.

The simultaneous in situ AN polymerization and $\mathrm{Ag}^{+}$reduction allows the formation of well monodispersed nanoparticles. We must recall that silver nitrate is well dispersed in acrylonitrile at

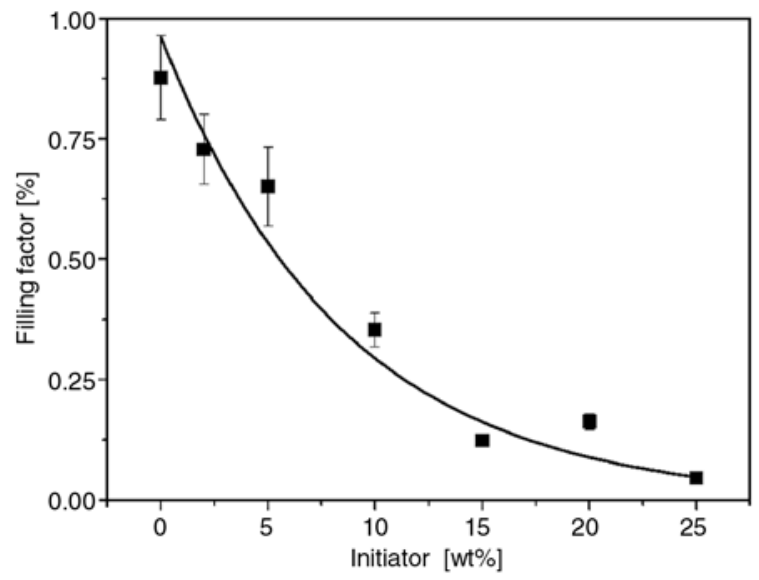

Figure 7. Photoinitiator dependent filling factor behaviour at constant metal precursor percentage $\left(\left[\mathrm{AgNO}_{3}\right]=15 \mathrm{wt} \%\right)$
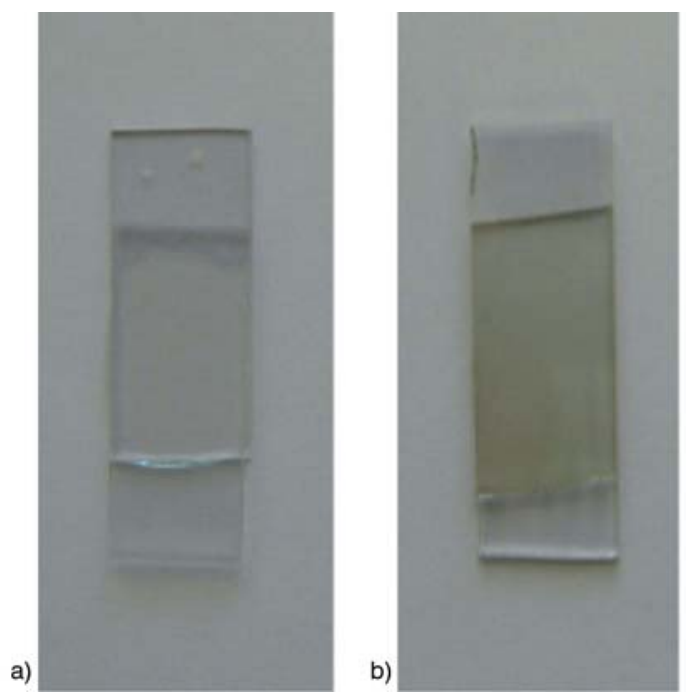

Figure 8. Pictures of samples with: a) $\left[\mathrm{AgNO}_{3}\right]=20 \mathrm{wt} \%$ and b) $\left[\mathrm{AgNO}_{3}\right]=30 \mathrm{wt} \%$. The initiator amount is $10 \mathrm{wt} \%$ in both samples.

room temperature without the use any other solvent.

\subsection{Electrical properties of PDMNPs}

The electrical properties of polymer dispersed metal nanoparticles are strongly influenced by the metal filling factor and nanoparticle sizes $[6,7]$.

The main electric conductivity mechanisms in PDMNPs are:

1. Ion conductivity, due to the ions remaining dispersed in the polymer matrix;

2. Electron conductivity in the metal nanoparticle network;

3. Tunnelling conductivity.

Generally, at high volume fractions of metal nanoparticles a 3D conducting network can develop in the matrix, leading to a sudden increase in the electric conductivity known as percolation. Our samples are characterized by rather low filling factors as shown in Figure 7, always far from percolation threshold. By comparing the conductivities of a sample containing $15 \mathrm{wt} \%$ of $\mathrm{AgNO}_{3}$ and $0 \mathrm{wt} \%$ of IN in its fluid (un-polymerized, $\sigma=0.45 \mu \mathrm{S} \cdot \mathrm{cm}^{-1}$ ) and solid (polymerized, $\sigma=7.2 \mu \mathrm{S} \cdot \mathrm{cm}^{-1}$ ) state, we observed that the conductivity of the fluid solution is almost two order of magnitude lower than the solid one. By taking into account that in the fluid solution:

1. there is no metal particle,

2. the electric conduction is ionic, 


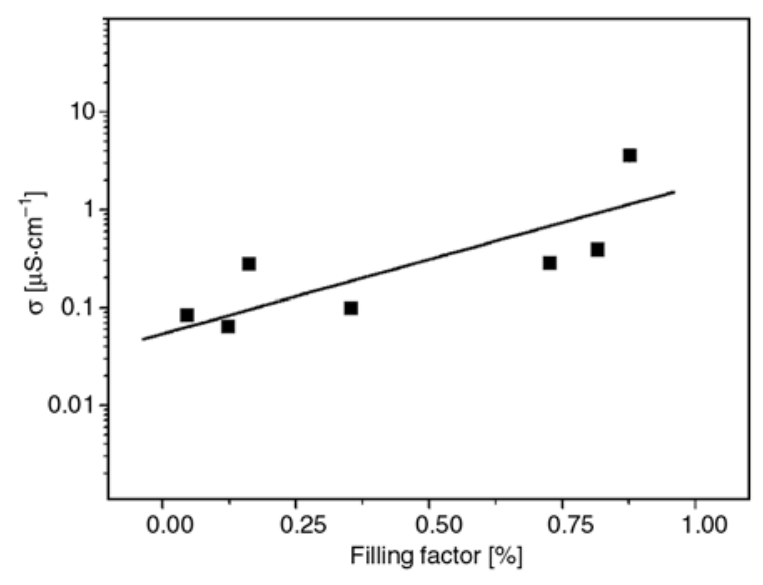

Figure 9. Conductivity behaviour of PDMNPs as a function of frequency for different initiator wt. percentage at constant metal precursor percentage $\left(\left[\mathrm{AgNO}_{3}\right]=15 \mathrm{wt} \%\right)$

3. ion mobility is larger than in the solid matrices we can state that at low frequencies the conduction in our polymerized samples is due to an electron transport through metal nanoparticles and the ionic conductivity is negligible.

Figure 9 shows the frequency dependent behaviour of film conductivity for different IN contents at a constant silver nitrate percentage $\left(\left[\mathrm{AgNO}_{3}\right]=\right.$ $15 \mathrm{wt} \%)$. Conductivities monotonically increase as a function of frequency and show larger values for larger IN amounts, i.e. in samples which are characterized by smaller nanoparticles.

If we report the behaviour of electric conductivity as a function of filling factor as previously calculated, we obtain the graph reported in Figure 10, where the conductivity increase for increasing values of filling factor, in agreement with the effective medium theoretical models $[3,6,25]$. Therefore, it is possible to gain the wanted film conductivity by

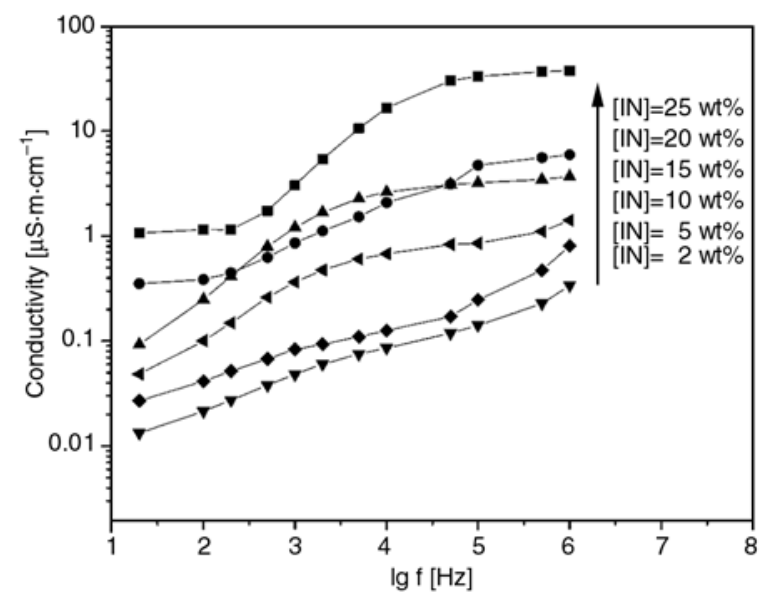

Figure 10. Filling factor dependent conductivity behaviour of PDMNPs changing both the photoinitiator and metal salt amounts in the starting mixtures.

\subsection{Optical properties of PDMNPs}

Metal nanocomposites generally exhibit particular optical properties originating from the strong interactions between incident light and metal nanoparticles, which result in collective oscillations of electron clouds at the interface of metal particles and polymer matrix (surface plasmons). The resonance frequency of such oscillations is strongly dependent on the metal, the surrounding polymer medium as well as the nanoparticle size and shape distribution. The light absorption range can vary from UV-Vis region up to infrared wavelengths. The tunability of optical absorption by an adequate tailoring of nanoparticle size and shape makes metal nanocomposites suitable for interesting electrooptical and photovoltaic applications [26, 27].

After UV irradiation of samples with increasing amounts of silver nitrate at constant weight percentage of inititator, we generally obtained transparent films in the range $400-700 \mathrm{~nm}$ indicating the absence of aggregates larger than $400 \mathrm{~nm}$. The formation of Ag nanoparticles during the polymerization was visually observed in samples (characterized by larger silver precursor amounts in the starting mixtures) by a chromatic change from colorless to yellow-brown as the amount of silver nitrate increases. The colour change was also confirmed by UV-Vis spectra (data not shown) characterized by an absorption peak around $420 \mathrm{~nm}$, which is due to plasmon resonance of larger silver nanoparticles, as already reported by Zhang and

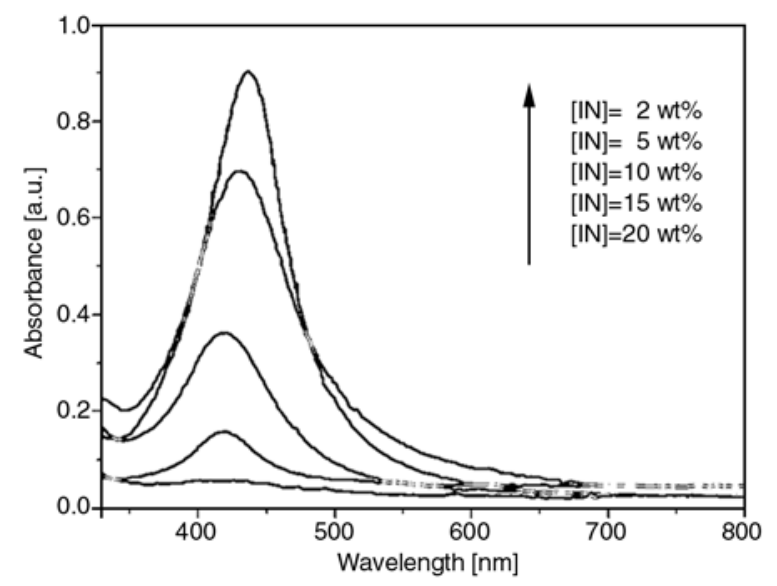

Figure 11. UV-Vis absorption spectra of PDMNPs for different amounts of photoinitiator $\left(\left[\mathrm{AgNO}_{3}\right]=15 \mathrm{wt} \%\right)$ 
Han [22]. We observed the typical red shift of absorption peak for larger $\mathrm{AgNO}_{3}$ amounts, too. We observed a similar behaviour when $\left[\mathrm{AgNO}_{3}\right]$ is kept constant and [IN] is reduced. In particular, the lower the IN concentration, the higher is the absorption peak. The UV-Vis absorption spectra for samples characterized by a silver nitrate amount of $15 \mathrm{wt} \%$ and different amount of photoinitiator are shown in Figure 11. In addition to the increase of absorption peak height, a clear red-shift in the absorption peak from 418 to $436 \mathrm{~nm}$ is observed as a function of decreasing IN content, indicating the particle size increase (which is consistent with TEM measurements, see above).

\section{Conclusions}

In this work we have shown that it is possible to finely control the morphology of polymer dispersed metal nanoparticles obtained by in situ polymerization of monomer and simultaneous metal ion reduction. The kinetics of polymerization and reduction reactions can be controlled by either using different amounts of metal precursor salt or changing the loading of photoinitiator in the starting mixtures, leading to different particle size and number density. The tuning of particle size and number density results in a fine tuning of both electrical and optical properties of PDMNP films allowing the manufacture of interesting electrooptical devices.

\section{Acknowledgements}

MIUR, the Italian Ministry for University is acknowledged for financial supports (Grant EX 60\%, PRIN 2008).

\section{References}

[1] Biswas A., Aktas O. C., Schürmann U., Saeed U., Zaporojtechenko V., Faupel F., Strunskus T.: Tunable multiple plasmon resonance wavelengths response from multicomponent polymer-metal nanocomposite systems. Applied Physics Letters, 84, 2655-2657 (2004).

DOI: $\underline{10.1063 / 1.1697626}$

[2] Convertino A., Capobianchi A., Valentini A., Cirillo E. N. M.: A new approach to organic solvent detection: High-reflectivity Bragg reflectors based on a gold nanoparticle/teflon-like composite material. Advanced Materials, 15, 1103-1105 (2003).

DOI: $\underline{10.1002 / \mathrm{adma} .200304777}$
[3] Ajayan P. M., Schadler L. S., Braun P. V.: Nanocomposite science and technology. Wiley, Weinheim (2003).

[4] Fan F-R. F., Bard A. J.: Chemical, electrochemical, gravimetric, and microscopic studies on antimicrobial silver films. Journal of Physical Chemistry B, 106, 279- 287 (2002). DOI: $10.1021 / \mathrm{jp} 012548 \mathrm{~d}$

[5] Ouyang J., Chu C-W., Szmanda R., Ma L., Yang Y.: Programmable polymer thin film and non-volatile memory device. Nature Materials, 3, 918-922 (2004). DOI: $\underline{10.1038 / \mathrm{nmat} 1269}$

[6] Du H., Chenb H., Gong J., Wang T. G., Sun C., Lee S. W., Wen L. S.: Use of effective medium theory to model the effect of the microstructure on dc conductivity of nano-titanium films. Applied Surface Science, 233, 99-104 (2004).

DOI: 10.1016/j.apsusc.2004.03.214

[7] Schürmann U., Takele H., Zaporojtechenko V., Faupel F.: Optical and electrical properties of polymer metal nanocomposites prepared by magnetron cosputtering. Thin Solid Films, 515, 801-804 (2006). DOI: $10.1016 /$ j.tsf.2005.12.249

[8] Ederth J., Johnsson P., Niklasson G. A., Hoel A., Hultåker A., Heszler P., Granqvist C. G., van Doorn A. R., Jongerius M. J., Burgard D.: Electrical and optical properties of thin films consisting of tin-doped indium oxide nanoparticles. Physical Review B, 68, 155410-155420 (2003). DOI: 10.1103/PhysRevB.68.155410

[9] Shenhar R., Norsten T. B., Rotello V. M.: Polymermediated nanoparticle assembly: Structural control and applications. Advanced Materials, 17, 657-669 (2005).

DOI: $10.1002 / \mathrm{adma} .200401291$

[10] Shiraishi Y., Toshima N.: Oxidation of ethylene catalyzed by colloidal dispersions of poly(sodium acrylate)-protected silver nanoclusters. Colloids Surface A: Physicochemical and Engineering Aspects, 169, 59-66 (2000). DOI: $\underline{10.1016 / \mathrm{S} 0927-7757(00) 00417-9}$

[11] Maye M. M., Chun S. C., Han L., Rabinovich D., Zhong C. J.: Novel spherical assembly of gold nanoparticles mediated by a tetradentate thioether. Journal of the American Chemical Society, 124, 4958-4959 (2002). DOI: $10.1021 / \mathrm{ja} 025724 \mathrm{k}$

[12] Giri A. K.: Magnetic properties of iron-polyethylene nanocomposites prepared by high energy ball milling. Journal of Applied Physics, 81, 1348-1350 (1997). DOI: $\underline{10.1063 / 1.363870}$

[13] Schürmann U., Hartung W. A., Takele H., Zaporojtchenko V., Faupel F.: Controlled syntheses of Agpolytetrafluoroethylene nanocomposite thin films by co-sputtering from two magnetron sources. Nanotechnology, 16, 1078-1082 (2005). DOI: $\underline{10.1088 / 0957-4484 / 16 / 8 / 014}$ 
[14] Takele H., Jebril S., Strunskus T., Zaporojtchenko V., Adelung R., Faupel F.: Tuning of electrical and structural properties of metal-polymer nanocomposite films prepared by co-evaporation technique. Applied Physics A: Materials Science and Processing, 92, 345-450 (2008).

DOI: $10.1007 / \mathrm{s} 00339-008-4524-0$

[15] Martinu L., Biederman H.: Monitoring the deposition process of metal-doped polymer films using optical emission spectroscopy. Plasma Chemistry and Plasma Processing, 5, 81-87 (1985).

DOI: $10.1007 / \mathrm{BF} 00567911$

[16] Brust M., Walker M., Bethell D., Schiffrin D., Whyman R.: Synthesis of thiol-derivatised gold nanoparticles in a two-phase liquid-liquid system. Journal of the Chemical Society, Chemical Communications, 1994/7, 801-802 (1994).

DOI: $10.1039 / C 39940000801$

[17] Liu H., Ge X., Ni Y., Ye Q., Zhang Z.: Synthesis and characterization of polyacrylonitrile-silver nanocomposites by $\gamma$-irradiation. Radiation Physics and Chemistry, 61, 89-91 (2001).

DOI: 10.1016/S0969-806X(00)00383-2

[18] Zhang Z., Zhang L., Wang S., Chen W., Lei Y.: A convenient route to polyacrylonitrile/silver nanoparticle composite by simultaneous polymerization-reduction approach. Polymer, 42, 8315-8318 (2001). DOI: $10.1016 / \mathrm{S} 0032-3861(01) 00285-3$

[19] Gandubert V. J., Lennox R. B.: Assessment of 4(dimethylamino)pyridine as a capping agent for gold nanoparticles. Langmuir, 21, 6532-6539 (2005). DOI: $10.1021 / \mathrm{la} 050195 \mathrm{u}$

[20] Majima T., Sakamoto M., Tachikawa T., Fujitsuka M., Majima T.: Two-color two-laser fabrication of gold nanoparticles in a PVA film. Chemical Physics Letters, 420, 90-94 (2006).

DOI: $10.1016 /$ j.cplett.2005.12.053
[21] Yagci Y., Sangermano M., Rizza G.: In situ synthesis of gold-cross-linked poly(ethylene glycol) nanocomposites by photoinduced electron transfer and free radical polymerization processes. Chemical Communications, 24, 2771-2773 (2008).

DOI: $10.1039 / \mathrm{b} 803279 \mathrm{c}$

[22] Zhang Z., Han M.: One-step preparation of sizeselected and well-dispersed silver nanocrystals in polyacrylonitrile by simultaneous reduction and polymerization. Journal of Materials Chemistry, 13, 641643 (2003).

DOI: $10.1039 / \mathrm{b} 212428 \mathrm{a}$

[23] Dey A., Karan S., De S. K.: Thermal and electric properties of $\mathrm{CeO} 2$ nanoparticles dispersed in polyethylene oxide: $\mathrm{NH}_{4} \mathrm{ClO}_{4}$ complex. Solid State Ionics, 178, 1963-1968 (2008).

DOI: $\underline{10.1016 / j . s s i .2007 .12 .063}$

[24] Hong S. U., Jin J. H., Wong J., Kang Y. S.: Polymersalt complexes containing silver ions and their application to facilitated olefin transport membranes. Advanced Materials, 12, 968-971 (2000).

DOI: $10.1002 / 1521-4095(200006) 12: 13<968:: A I D-$ ADMA968>3.0.CO;2-W

[25] Heilmann A.: Polymer films with embedded metal nanoparticles. Springer, Berlin, (2003).

[26] Westphalen M., Kreibig U., Rostalski J., Luth H., Meissner D.: Metal cluster enhanced organic solar cells. Solar Energy Materials and Solar Cells, 61, 97-105 (2000). DOI: $\underline{10.1016 / \mathrm{S} 0927-0248(99) 00100-2}$

[27] Pillai S., Catchpole K. R., Trupke T., Green M. A.: Surface plasmon enhanced silicon solar cells. Journal of Applied Physics, 101, 093105/1-0931105/8 (2007). DOI: $\underline{10.1063 / 1.2734885}$ 